\title{
Efeito da Adição de Enzimas em Dietas de Frangos de Corte à Base de Milho e Farelo de Soja sobre a Digestibilidade Ileal de Nutrientes ${ }^{1}$
}

\author{
Anel Atencio Tejedor², Luiz Fernando Teixeira Albino ${ }^{3}$, Horacio Santiago Rostagno³, \\ Cristina Amorim Ribeiro de Lima², Flávio Medeiros Vieites ${ }^{2}$
}

\begin{abstract}
RESUMO - Dois experimentos, utilizando pintos de corte Avian Farm, no período de 8 a 18 dias de idade, foram realizados para se avaliar o efeito de enzimas microbianas sobre os coeficientes de digestibilidade (CD) ileal aparente da matéria seca (MS), da proteína bruta (PB), da energia bruta (EB), do fósforo (P) e do cálcio (Ca) de dietas à base de milho e farelo de soja com diferentes níveis de Ca e P disponível $\left(\mathrm{P}_{\mathrm{d}}\right)$. Óxido crômico $(0,5 \%)$ foi adicionado às dietas a fim de se estimar o fator de indigestibilidade. Todas as aves foram abatidas aos 19 dias, para a coleta da digesta. O primeiro experimento foi realizado em arranjo fatorial 2 x 2, com seis repetições contendo 10 aves. As dietas foram formuladas contendo dois níveis de Ca e $\mathrm{P}_{\mathrm{d}}$ normal $\left(1 \% \mathrm{Ca} / 0,45 \% \mathrm{P}_{\mathrm{d}}\right)$ e baixo $\left(0,70 \% \mathrm{Ca} / 0,32 \% \mathrm{P}_{\mathrm{d}}\right)$ x dois níveis de enzima fitase $(0$ e $1 \mathrm{~kg} / \mathrm{t}$ de ração). O segundo experimento foi realizado em arranjo fatorial 2 x 3 , sendo dois níveis de Ca e $\mathrm{P}_{\mathrm{d}}$ normal $\left(1 \% \mathrm{Ca} / 0,45 \% \mathrm{P}_{\mathrm{d}}\right) \mathrm{e}$ baixo $\left(0,70 \% \mathrm{Ca} / 0,32 \mathrm{P}_{\mathrm{d}} \%\right)$ e três combinações de enzimas: complexo multienzimático $(\mathrm{CM})$ com fitase (Fit): $0 \mathrm{~kg} / \mathrm{t}$ para o controle, $2 \mathrm{~kg} / \mathrm{t}(\mathrm{CM})$ e $2 \mathrm{~kg} / \mathrm{t}$ mais $1 \mathrm{~kg} / \mathrm{t}$ de fitase (CM+Fit), com seis repetições, contendo 10 aves cada. No experimento 1 , a adição de fitase melhorou a digestibilidade ileal da MS (5,2\%), PB (2,4\%) e EB (3,8\%). Interação significativa foi observada na digestibilidade do Ca e P, sendo que adição da fitase melhorou a digestibilidade do Ca e $\mathrm{P}$ em ambos níveis de $\mathrm{Ca}$ e P. No segundo experimento, a adição do CM melhorou o CD da PB, Pe Ca em 3; 4,7; e 7,8\%, respectivamente. A associação do CM+fitase mostrou efeito aditivo no aproveitamento do Ca e P. Interação foi observada para o CD da EB, a adição do CM melhorou a digestibilidade em ambos níveis de $\mathrm{Ca}$ e $\mathrm{Pd}$, entretanto o $\mathrm{CM}+\mathrm{fitase}$ melhorou o CD da EB apenas no nível baixo de Ca e P.
\end{abstract}

Palavras-chave: amilase, celulase, fitase, digestibilidade, frangos de corte, protease

\section{Effect of Enzymes Supplementation in Corn Soybean Meal Broiler Diets on Ileal Digestibility of Nutrients}

\begin{abstract}
Two experiments, using 8 to 18 days old Avian -Farm male broiler chicks, were conducted to evaluate the effect of microbial enzymes on the ileal digestibility coefficient (DC) of dry mater (DM), crude protein (CP), energy (E), calcium (Ca) and phosphorus (P) in corn soybean meal diets with different level of $\mathrm{Ca}$ and available $\mathrm{P}\left(\mathrm{P}_{\mathrm{a}}\right)$. Chromic oxide $(0,5 \%)$ was added to the diets, as an indigestible marker, to estimate ileal digestibility. All chicks were killed at the end of the experiments (19 days) to collect the ileal content. The first experiment was a factorial arrangement of $2 \times 2$, with six replicates ( $n=240,10$ chicks per unit). Diets were formulated to contain two levels of $\mathrm{Ca}$ and $\mathrm{P}_{\mathrm{a}}$ normal $\left(1 \% \mathrm{Ca} / 0.45 \% \mathrm{P}_{\mathrm{a}}\right)$ and low $\left(0.70 \% \mathrm{Ca} / 0.32 \% \mathrm{P}_{\mathrm{a}}\right) \mathrm{x}$ two level of phytase $(\mathrm{Phy})$ enzyme $(0$ and $1 \mathrm{~kg} / \mathrm{t}$ of diet $)$. The second experiment was a factorial arrangement of $2 \times 3$, six replicates $(n=360,10$ chicks per unit). Diets were formulated with two levels of Ca and $\mathrm{P}_{\mathrm{a}}$ normal $\left(1 \% \mathrm{Ca} / 0.45 \% \mathrm{P}_{\mathrm{a}}\right)$ and low $\left(0.70 \% \mathrm{Ca} / 0.32 \% \mathrm{P}_{\mathrm{a}}\right) \mathrm{x}$ three combination of a multienzyme complex (MC). The combination were $0 \mathrm{~kg} / \mathrm{t}$ for the control (C), $2 \mathrm{~kg} / \mathrm{t}$ (MC) and $2 \mathrm{~kg} / \mathrm{t}$ of the MC plus $1 \mathrm{~kg} / \mathrm{t}$ of phy (MC+phy). In the first experiment the diets with Phy had a higher digestibility for DM (5.2\%), CP (2.4\%) and GE (3,8\%). Phytase improve the digestibility of P and Ca in both levels of Ca and $\mathrm{P}_{\mathrm{a}}$. In the second experiment, the addition of the MC improved DC of CP, $\mathrm{P}$ and $\mathrm{Ca}$ in 3\%; 4.7 and 7.8\%, respectively. The association of $\mathrm{MC}+\mathrm{Phy}$ improved $\mathrm{Ca}$ and $\mathrm{P}$ digestibility. Interaction was observed in the energy digestibility. The addition of the MC improved the digestibility in both $\mathrm{Ca}$ and $\mathrm{P}$ levels, however the addition of the $\mathrm{CM}+\mathrm{Phy}$ improved energy $\mathrm{DC}$ only in the diets with low Ca and $\mathrm{P}$ levels.
\end{abstract}

Key Words: amillase, broiler chicks, cellulase, digestibility, protease, phytase

\section{Introdução}

$\mathrm{Na}$ avicultura, as enzimas exógenas, produzidas por microrganismos, vêm sendo estudadas com freqüência, devido à ausência ou à produção insuficiente de algumas enzimas endógenas capazes de atuar na digestão de certos componentes encontrados nos alimentos de origem vegetal (CANTOR, 1995). Como exemplo, citamse os ingredientes ricos em fósforo fítico ou em polissacarídeos não-amiláceos (NSP), os quais podem ser considerados fatores antinutricionais e, portanto, não podem ser digeridos eficientemente pelas aves.

\footnotetext{
1 Parte da tese de Mestrado apresentada à UFV pelo primeiro autor.

2 Estudante de Doutorado do DZO - UFV, CEP: 36571-000, Viçosa - MG. E.mail: anel@alunos.ufv.br

3 Professor do DZO-UFV, CEP: 36571-000, Viçosa - MG. Bolsista do CNPq.
} 
A presença de compostos polissacarídeos nãoamiláceos determina aumento da viscosidade do alimento, em nível do trato gastrointestinal, o que origina reduções na digestão e absorção de aminoácidos, carboidratos, minerais e outros nutrientes, com conseqüente queda na produtividade das aves (BEDFORD et al., 1991).

A suplementação de enzimas em dietas de aves à base de milho e farelo de soja mostraram pouca o nenhuma influência sobre a digestibilidade de nutrientes. Recentemente, ZANELLA et al. (1999) mostraram claramente que a digestibilidade e o desempenho das aves foram melhorados pela adição de complexos multienzimáticos (amilase, protease, xilanase) em dietas à base de milho e farelo de soja. MARSMANN et al. (1997) também observaram que a adição de enzimas protease e carboidrase, juntas ou separadas, em dietas à base de farelo de soja melhoraram a digestibilidade das proteínas e dos polissacarídeos não-amiláceos.

Outro fator antinutricional para monogástricos, a molécula de fitato, possui em sua estrutura grupos ortofosfatos altamente ionizáveis, os quais afetam a disponibilidade de cátions como o cálcio, zinco, cobre, magnésio e ferro, no trato gastrointestinal, o que resulta na formação de complexos insolúveis (SEBASTIAN et al., 1997, 1998; RIMBACH e PALLAUF, 1998; e SOHAIL e ROLAND, 1999). Os grupos ortofosfatos podem também unir-se a enzimas digestivas e proteínas dietéticas, reduzindo a digestibilidade de carboidratos e aminoácidos (FERKET, 1993; SEBASTIAN et al., 1996; e RAVINDRAN et al., 1999).

$\mathrm{O}$ fato de as enzimas serem específicas em suas reações determina que os produtos que tenham só uma enzima sejam insuficientes para produzir o máximo beneficio. Isto sugere que misturas de enzimas sejam mais efetivas no aproveitamento dos nutrientes das dietas. Em função disso, vários estudos vêm sendo realizados com a adição de enzimas exógenas, particularmente na forma de "complexo multienzimático".

O objetivo deste trabalho foi determinar o efeito da adição de um complexo multienzimático contendo protease, amilase e celulase e fitase sobre os coeficientes de digestibilidade ileal aparente da matéria seca, da proteína bruta, da energia bruta, do fósforo e do cálcio e os valores de energia digestível ileal aparente das rações, em ensaio com pintos de corte.

\section{Material e Métodos}

Realizaram-se dois ensaios biológicos, no período de 31/03/99 a 11/04/99, utilizando-se o "método de coleta de digesta ileal". A temperatura média registrada foi de $26^{\circ} \mathrm{C}$ e a média das mínimas e máximas, de 23 e $29^{\circ} \mathrm{C}$, respectivamente.

Nos dois ensaios, foram utilizados 600 pintos de corte, machos, da linhagem Avian Farm, com oito dias de idade e peso médio de $147 \mathrm{~g}$. As rações experimentais (Tabela 1) à base de milho e farelo de soja foram elaboradas de acordo com as recomendações de ROSTAGNO et al. (1996).

O delineamento utilizado no experimento 1 foi o inteiramente casualizado, em um arranjo fatorial 2x2 (dois níveis de Ca e $\mathrm{P}_{\mathrm{d}} \times$ dois níveis de fitase) e seis repetições de 10 aves por unidade experimental totalizando 240 aves. Os níveis de $\mathrm{Ca}$ e $\mathrm{P}_{\mathrm{d}}$ utilizados foram normais $\left(1 \% \mathrm{Ca} / 0,45 \% \mathrm{P}_{\mathrm{d}}\right)$ e baixos $\left(0,70 \% \mathrm{Ca} / 0,32 \% \mathrm{P}_{\mathrm{d}}\right)$. Os níveis de fitase (Allzyme phytase ${ }^{\circledR}$ ) utilizados em ambos ensaios foram 0 para o controle e $1 \mathrm{~kg} / \mathrm{t}$ de dieta, de acordo com as recomendações da indústria.

No experimento 2, foi utilizado o delineamento experimental inteiramente casualizado, em um arranjo fatorial $2 \times 3$, seis repetições de 10 aves por unidade experimental, totalizando 360 ave, sendo dois níveis de $\mathrm{Ca}$ e $\mathrm{P}_{\mathrm{d}}$ normal $\left(1,00 \% \mathrm{Ca} / 0,45 \% \mathrm{P}_{\mathrm{d}}\right)$ e baixo $\left(0,70 \% \mathrm{Ca} / 0,32 \% \mathrm{P}_{\mathrm{d}}\right)$, e três combinações do complexo multienzimático (amilase, celulase, protease), mais fitase (Fit). As combinações foram $0 \mathrm{~g} / \mathrm{kg}$ para o controle (C), $2 \mathrm{~kg} / \mathrm{t}$ do CM e $2 \mathrm{~kg} / \mathrm{t}$ do $\mathrm{CM}+1 \mathrm{~kg} / \mathrm{t} \mathrm{de}$ fitase $(\mathrm{CM}+\mathrm{Fit})$, de acordo com as recomendações do fabricante. A dosagem do CM (Vegpro $\left.{ }^{\circledR}\right)$ foi em função do farelo de soja e a da fitase (Allzyme phytase $\left.{ }^{\circledR}\right)$, em função da ração. Ressalta-se que o farelo de soja utilizado no experimento dois foi considerado com $7 \%$ a mais de energia e aminoácidos, visando obter dietas ligeiramente deficientes em aminoácidos e energia.

As rações foram misturadas com $0,5 \%$ de óxido crômico $\left(\mathrm{Cr}_{2} \mathrm{O}_{3}\right)$, em misturador em $\mathrm{Y}$, como indicador indigestível para a determinação do fator de indigestibilidade.

Até os oito dias de idade, as aves receberam ração inicial para frangos de corte e ficaram alojadas em um galpão de alvenaria. Após esse período, os pintos foram transferidos para baterias frias com $225 \mathrm{~cm}^{2}$ de área ( $45 \mathrm{~cm}$ de largura, $50 \mathrm{~cm}$ de comprimento e 40 de altura), em estrutura metálica, consti- 
Rev. bras. zootec.

Tabela 1 - Composição das dietas experimentais (\% matéria natural)

Table 1 - Composition of the reference diet (\% fed basis)

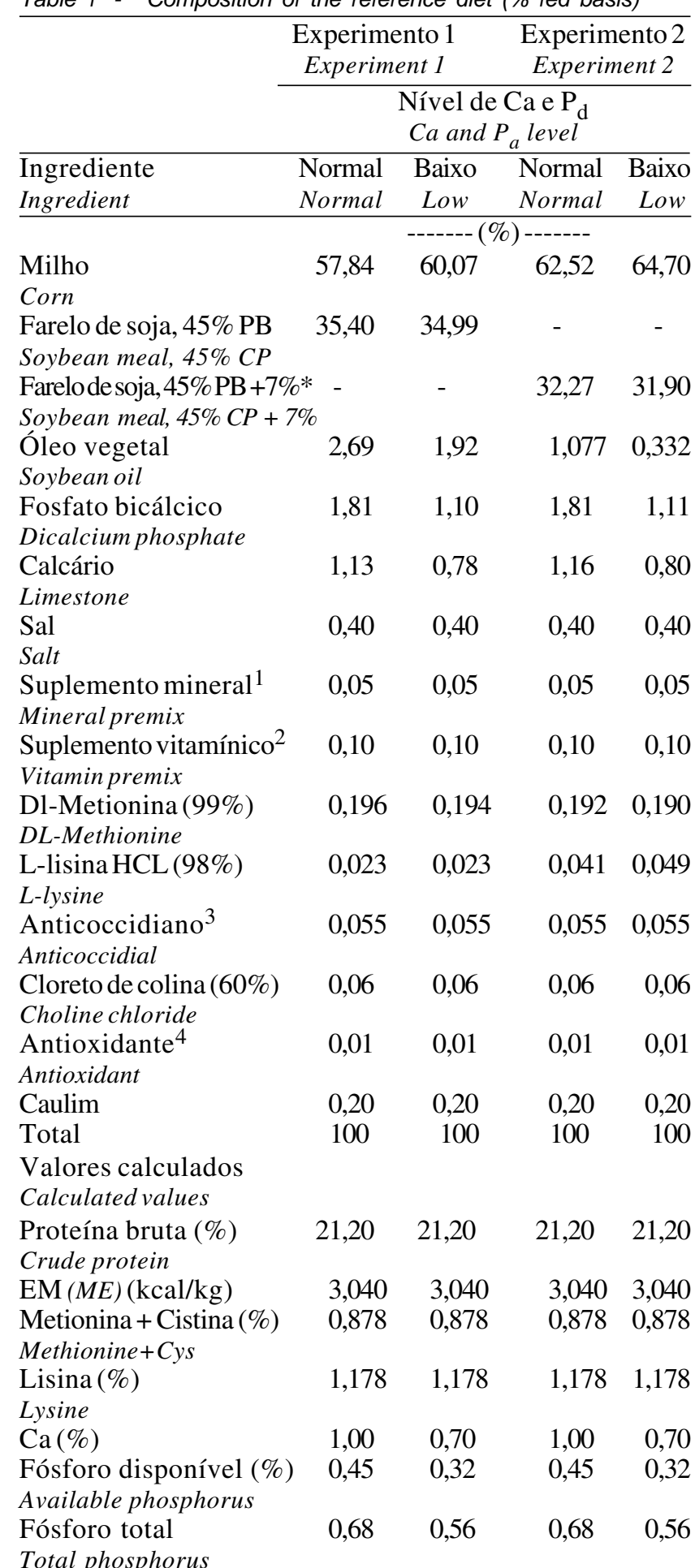

1 Premix mineral contendo: Ferro (Iron), 100,0 g; Cobalto, 2,0 g; Cobre (Copper), 20,0 g; Manganês (Manganese), 160 g; Zinco (Zinc) $100 \mathrm{~g}$; lodo (lodine), 2, $0 \mathrm{~g}$; Excipiente q.s.p., $500 \mathrm{~g}$.

2 Premix vitaminínico contendo: Vit. A, 10.000 .000 U.I; Vit. $D_{3}$, 2.000.000 U.I; Vit. E, 30.000 U.I; Vit. $B_{1}, 2,0$ g; Vit. B $, 6,0$ g; Vit. $B_{6}$, $4,0 \mathrm{~g}$; Vit. $\mathrm{B}_{12}, 0,015 \mathrm{~g}$; Ác. Pantotênico (Pantothenic acid), 12,0 g; Biotina (Biotin), 0,1 g; Vit. K $3,3,0$ g; Ác. fólico (Folic acid), 1,0 g; Ác. Nicotínico (Nicotinic acid), 50,0 g; Selênio (Selenium), 250,0 mg; Excipiente q.s.p., $1000 \mathrm{~g}$.

3 Maduramicina.

4 Butil hidroxi tolueno $99 \%$.

* Experimento 2: farelo de soja considerado com 7\% a mais de EM e aminoácidos.

* Experiment2:MEandaminoacid valuesforsoybeanmea/were increasedby $7 \%$. tuídas de compartimentos distribuídos em dois andares. Estas baterias, em número de quatro, estavam dispostas em uma sala de $68 \mathrm{~m}^{2}$, com 2,80 m de pé direito e grandes janelas de vidro. Para maior conforto dos animais, foram utilizados dois aquecedores elétricos à noite, durante todo o período experimental.

O período experimental foi de 8 a 18 dias, no qual as aves receberam água e ração à vontade. Aos 19 dias de idade, todas as aves de cada repetição dos dois ensaios foram abatidas por deslocação cervical e imediatamente disseccionadas para obtenção da digesta, desde um ponto $5 \mathrm{~cm}$ antes da junção íleocecal até $15 \mathrm{~cm}$ em direção ao duodeno. Este segmento de $15 \mathrm{~cm}$ foi seccionado transversalmente e seu conteúdo, retirado e colocado dentro de um copo plástico.

As digestas coletadas nos copos plásticos foram identificadas, pesadas e, posteriormente, armazenadas em congelador para posteriores análises de matéria seca, proteína bruta, energia bruta, fósforo, cálcio e cromo. Todas as análises foram realizadas em duplicatas no Laboratório de Nutrição Animal do Departamento de Zootecnia da UFV, por intermédio da metodologia descrita por SILVA (1990).

Uma vez obtidos os resultados de análises laboratoriais das rações e da digesta, foram calculados os coeficientes de digestibilidade ileal aparente de matéria seca, proteína bruta, energia bruta, fósforo e cálcio e os valores de energia digestível ileal aparente. Os coeficientes de digestibilidade e de energia digestível foram determinados com base nos níveis de cromo nas dietas e na digesta, por meio do cálculo do fator de indigestibilidade.

Os dados experimentais obtidos foram submetidos à análise de variância e à comparação de médias, utilizando-se o teste utilizando-se o teste F e Student-Newman-Keul (SNK) do programa estatístico SAS (1996).

\section{Resultados e Discussão}

\section{Experimento 1}

Os coeficientes de digestibilidade ileal aparente da matéria seca (MS), da proteína bruta (PB), da energia bruta (EB), do fósforo $(\mathrm{P})$ e do cálcio $(\mathrm{Ca})$ são apresentados na Tabela 2.

A adição da enzima fitase melhorou $(\mathrm{P}<0,05)$ a digestibilidade ileal da MS, PB e EB em 5,2; 2,4; e $3,8 \%$, respectivamente. Estes resultados confirmam o efeito benéfico da fitase microbiana sobre a hidrólise 
do ácido fítico, incrementando a digestibilidade ileal de nutrientes nas dietas de frangos. As bases para estes achados estão se tornando evidentes e claramente relacionadas com a capacidade do ácido fítico em se ligar a proteínas, aminoácidos, amido e lipídios e da habilidade da enzima em liberar os nutrientes complexados à molécula, pela hidrólise do ácido fítico (RAVINDRAN et al.,1999).

A média dos valores de digestibilidade ileal da matéria seca e da energia bruta foram maiores $(\mathrm{P}<0,05)$ em rações com baixos níveis de Ca e $\mathrm{P}_{\mathrm{d}}$, no entanto, para proteína bruta, os maiores valores foram observados nas dietas com baixo nível de $\mathrm{Ca}$ e $\mathrm{P}_{\mathrm{d}}$ $(P>0,05)$. SEBASTIAN et al. (1997) não observaram diferença estatística entre os níveis de Ca e $\mathrm{P}_{\mathrm{d}}$, dentro do requerimento e dos níveis subótimos, para a digestibilidade da proteína bruta em frangos de corte, contudo, os maiores valores de digestibilidade foram encontrados para os níveis normais, concordando com estes achados.

Interação significativa entre a fitase e o nível de $\mathrm{Ca}$ e $\mathrm{P}_{\mathrm{d}}$ foi observada para os coeficientes de digestibilidade ileal do cálcio e fósforo $(\mathrm{P}<0,05)$. É importante mencionar que, no presente experimento, a adição da fitase melhorou a digestibilidade do $\mathrm{Ca}$ e $\mathrm{P}$ para ambos os níveis de $\mathrm{Ca}$ e $\mathrm{P}_{\mathrm{d}}$.

Ao analisar os valores de energia digestível ileal aparente $\left(\mathrm{EDI}_{\mathrm{ap}}\right)$, Tabela 3 , observa-se que os baixos níveis de $\mathrm{Ca}$ e $\mathrm{P}_{\mathrm{d}}$ apresentaram maiores valores de $\mathrm{EDI}_{\mathrm{ap}}$ e a presença da fitase melhorou $(\mathrm{P}<0,05)$ a energia digestível ileal aparente, em média, de $121 \mathrm{kcal} / \mathrm{kg}$ de MS, ou seja, melhora de 3,8\%. NAMKUNG e LEESON (1999) encontraram incremento de $1 \%$ na EMA $\mathrm{n}$ e BIEHL e BAKER (1997) não observaram melhora na digestibilidade da $\mathrm{EMV}_{\mathrm{n}}$, com adição na dieta de 600 e 1200 FTU/ $\mathrm{kg}$ de fitase microbiana, utilizando galos cecectomizados. Os resultados sugerem que adição de fitase microbiana à ração inicial de frangos de corte melhora os valores de digestibilidade da energia, em rações com níveis baixos de cálcio e fósforo.

$\mathrm{O}$ aumento nos coeficientes de digestibilidade de $\mathrm{PB}, \mathrm{Ca}, \mathrm{P}$ e EB, pela adição da fitase, indica, claramente, que maiores complexos de nutriente-fitato foram hidrolisados. O efeito da fitase microbiana sobre a digestibilidade da proteína e dos minerais deve ser quantificado, para permitir sua inclusão na formulação das dietas, visando reduzir os custos com alimentação. A digestibilidade da proteína e a concentração do ácido fítico dos alimentos são os dois fatores que determinam a magnitude deste efeito.

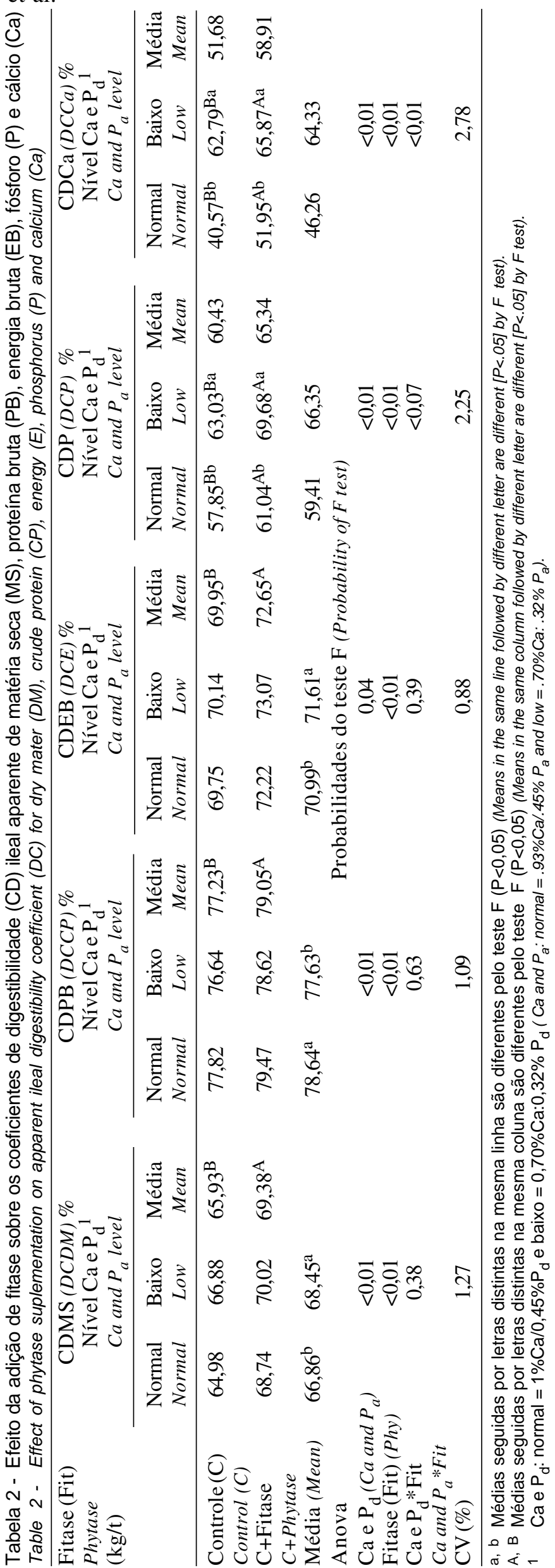


Rev. bras. zootec.

Tabela 3 - Efeito da adição de fitase sobre os valores de energia digestível ileal aparente das rações, expressos em $\mathrm{kcal} / \mathrm{kg}$ de matéria seca

Table 3 - Effect ofenzyme suplementation on the value of apparent ileal digestible of energy (apIDE)

\begin{tabular}{|c|c|c|c|}
\hline \multirow[t]{3}{*}{$\begin{array}{l}\text { Fitase } \\
\mathrm{kg} / \mathrm{t}\end{array}$} & \multicolumn{3}{|c|}{$\begin{array}{l}\mathrm{EDI}_{\mathrm{ap}} \\
I D E_{a p}^{\mathrm{ap}}\end{array}$} \\
\hline & \multicolumn{3}{|c|}{$\begin{array}{l}\text { Nível Ca e } \mathrm{P}_{\mathrm{d}}^{1} \\
\text { Ca e } P_{a} \text { level }\end{array}$} \\
\hline & $\begin{array}{l}\text { Normal } \\
\text { Normal }\end{array}$ & $\begin{array}{l}\text { Baixo } \\
\text { Low }\end{array}$ & $\begin{array}{c}\text { Média } \\
\text { Mean }\end{array}$ \\
\hline $\begin{array}{l}\text { Controle }(\mathrm{C}) \\
\text { Control }(C)\end{array}$ & 3154 & 3156 & $3155^{\mathrm{B}}$ \\
\hline $\begin{array}{l}\mathrm{C}+1 \\
\text { Média }\end{array}$ & $\begin{array}{l}3264 \\
3209^{b}\end{array}$ & $\begin{array}{l}3287 \\
3222^{\mathrm{a}}\end{array}$ & $3276^{\mathrm{A}}$ \\
\hline Mean & & & \\
\hline Anova & \multicolumn{3}{|c|}{$\begin{array}{c}\text { Probabilidade do teste } \mathrm{F} \\
\text { Probability of F test }\end{array}$} \\
\hline $\begin{array}{l}\text { Ca e } \mathrm{P}_{\mathrm{d}} \\
\text { Ca and } P_{a}\end{array}$ & \multicolumn{3}{|c|}{0,91} \\
\hline Fitase (Fit) & \multicolumn{3}{|c|}{$<0,01$} \\
\hline $\begin{array}{l}\text { Phytase-Phy } \\
\text { Ca e } \mathrm{P}_{\mathrm{d}} * \text { Fit } \\
\text { Ca and } P+P h y\end{array}$ & \multicolumn{3}{|c|}{0,42} \\
\hline $\mathrm{CV}(\%)$ & \multicolumn{3}{|c|}{0,88} \\
\hline
\end{tabular}

a, b Médias seguidas por letras distintas na mesma linha são diferentes pelo teste $F(P<0,05)$.

A, B Médias seguidas por letras distintas na mesma coluna são diferentes pelo teste $F(P<0,01)$.

1 Níveis Ca e $\mathrm{P}_{\mathrm{d}}$ : normal $=0,93 \% \mathrm{Ca} / 0,45 \% \mathrm{P}_{\mathrm{d}}$ e baixo $=0,80 \% \mathrm{Ca} /$ $0,33 \% P_{d}$.

$a, b \quad$ Means in the same line followed by different letter are different $(P<.05)$ by $F$ test.

$A, B$ Means in the same column followed by different letter are different $(P<.05)$ by $F$ test.

$1 \mathrm{Ca}$ and $P_{a}:$ Normal $=.93 \% \mathrm{Ca} / .45 \% P_{a}$ and low $=.80 \% \mathrm{Ca}: .33 \% P_{a}$.

\section{Experimento 2}

Os coeficientes de digestibilidade ileal aparente da matéria seca (MS), da proteína bruta (PB), da energia bruta (EB), do fósforo $(\mathrm{P})$ e do cálcio $(\mathrm{Ca})$ são apresentados na Tabela 4 e os valores energia digestível ileal, na Tabela 5.

Observou-se interação $(\mathrm{P}<0,05)$ entre a adição das enzimas e os níveis de Ca e $\mathrm{P}_{\mathrm{d}}$ para os coeficientes de digestibilidade da MS e EB. A adição do complexo multienzimático $(\mathrm{CM})$ melhorou $(\mathrm{P}<0,05)$ a digestibilidade ileal da MS somente no nível normal de $\mathrm{Ca}$ e $\mathrm{P}_{\mathrm{d}}$, enquanto seu efeito sobre a digestibilidade ileal de EB ocorreu nos dois níveis de $\mathrm{Ca}$ e $\mathrm{P}_{\mathrm{d}}$ avaliados. Já a adição do $\mathrm{CM}+$ fitase melhorou $(\mathrm{P}<0,05)$ a digestibilidade ileal da MS, indiferente do nível de $\mathrm{Ca}$ e $\mathrm{P}_{\mathrm{d}}$ avaliado, e a da $\mathrm{EB}$, somente na ração com níveis baixos de $\mathrm{Ca}$ e $\mathrm{P}_{\mathrm{d}}$, em que seu efeito foi superior $(\mathrm{P}<0,05)$ inclusive aquele obtido com a suplementação do CM. Estes resultados sugerem que pode haver efeito aditivo entre o $\mathrm{CM}$ e a fitase nas dietas com baixos níveis de $\mathrm{Ca}$ e $\mathrm{P}_{\mathrm{d}}$, melhorando a digestibilidade ileal de nutrientes.

Nos níveis normais de $\mathrm{Ca}$ e $\mathrm{P}_{\mathrm{d}}$, não se observou melhora $(\mathrm{P}>0,05)$ nos resultados de digestibilidade da MS e EB entre a adição do $\mathrm{CM}$ e $\mathrm{CM}+$ Fit na dieta, mostrando que, possivelmente, o efeito da associação das enzimas é mais expressivo em dietas com níveis abaixo do requerimento que em dietas contendo níveis normais de $\mathrm{Ca}$ e $\mathrm{P}_{\mathrm{d}}$. Na análise do fator enzima dentro dos níveis de $\mathrm{Ca}$ e $\mathrm{P}_{\mathrm{d}}$, observou-se que o nível normal de $\mathrm{Ca}$ e $\mathrm{P}_{\mathrm{d}}$ apresentou melhores resultados numéricos $(\mathrm{P}>0,05)$ que o nível baixo, para a digestibilidade da MS e EB.

Os resultados encontrados no aumento da digestibilidade ileal da energia bruta, neste experimento, concordam com os encontrados por ZANELLA et al. (1999), que observaram aumento significativo $(\mathrm{P}<0,05)$ na digestibilidade ileal do amido e gordura de 2 e $1,8 \%$, respectivamente.

Não foi evidenciada interação $(\mathrm{P}>0,05)$ entre a adição da enzima e os diferentes níveis de $\mathrm{Ca}$ e $\mathrm{P}_{\mathrm{d}}$, para os coeficientes de digestibilidade de $\mathrm{PB}, \mathrm{Ca}$ e $\mathrm{P}$. No entanto, a adição do $\mathrm{CM}$ melhorou significativamente $(\mathrm{P}<0,05)$ a digestibilidade de PB $(3 \%), \mathrm{P}(5 \%)$ e $\mathrm{Ca}(8 \%)$, quando comparados ao grupo controle. Quando a enzima fitase foi adicionada $(\mathrm{CM}+\mathrm{Fit})$, observou-se melhora $(\mathrm{P}<0,05)$ na digestibilidade do $\mathrm{P}$ $(4,2 \%)$ e $\mathrm{Ca}(4,7 \%)$, em comparação ao grupo que recebeu apenas o CM. Estes resultados reforçam o provável efeito aditivo encontrado com a adição da fitase e concordam com os achados de ZANELLA et al. (1999), que obtiveram incremento de $3 \%$ na digestibilidade da PB, com a adição de um complexo multienzimático (protease, amilase e xilanase), e MARSMANN et al. (1997), os quais também observaram que a adição de protease e carboidrase no farelo de soja melhorou a digestibilidade da PB e dos polissacarídeos não-amiláceos.

BIEHL e BAKER (1997) relataram que a eficácia da fitase depende do balanço de AAs na dieta e da origem da proteína utilizada. Observaram que a adição de $1,200 \mathrm{FTU} / \mathrm{kg}$ de fitase na dieta à base de farelo de soja, deficiente em AAs, aumentou em $2 \%$ a digestibilidade verdadeira dos AAs, utilizando galos cecectomizados, no entanto não foi tão expressiva quando a dieta estava dentro dos requerimentos. Esta talvez seja uma das explicações do comportamento aditivo encontrado com adição de fitase neste experimento.

$\mathrm{O}$ aumento no aproveitamento do $\mathrm{P}$, pela associação de enzimas, não-estudado na literatura até o presente, pode ser explicado da seguinte maneira: na 


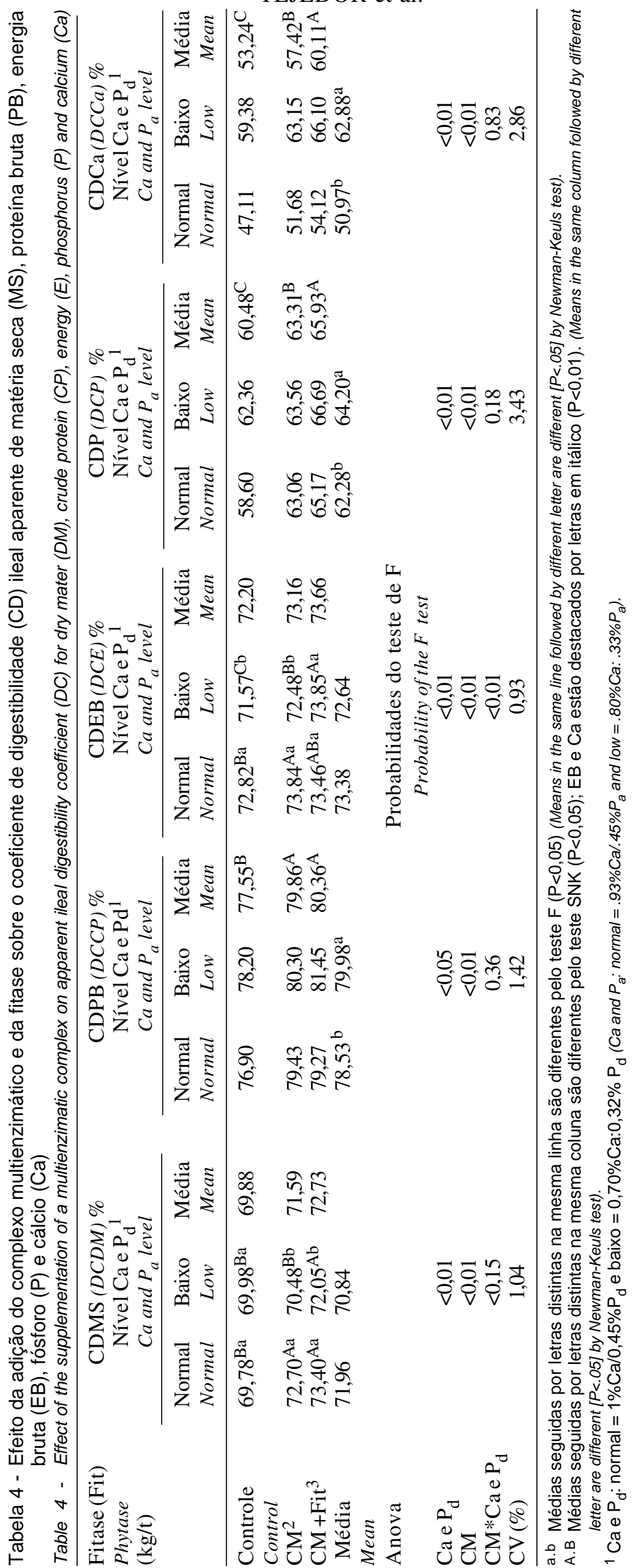


Rev. bras. zootec.

maioria dos grãos de monocotiledôneas, o fitato forma parte das camadas externas e nos grãos das dicotiledôneas, encontra-se no endosperma. Talvez, o rompimento destas estruturas pelas enzimas utilizadas (proteases, amilase e celulase) permita a liberação do fitato e outros nutrientes, facilitando a atuação da enzima fitase.

$\mathrm{Na}$ comparação do fator $\mathrm{Ca}$ e $\mathrm{P}_{\mathrm{d}}$, contrariamente aos resultados encontrados para a digestibilidade de MS e EB, o nível baixo melhorou $(\mathrm{P}<0,05)$ os coeficientes de digestibilidade de $\mathrm{PB}, \mathrm{P}$ e Ca.

Os resultados para a energia digestível ileal aparente (Tabela 3) foram iguais aos encontrados para os coeficientes de digestibilidade da energia (Tabela 5). No entanto, na comparação de médias, observou-se que houve aumento (1\%) de $42 \mathrm{kcal} / \mathrm{kg}$ de MS, com adição do CM, e de $64 \mathrm{kcal} / \mathrm{kg}$ de MS, com adição do $\mathrm{CM}+$ Fit. (2\%). Pode-se observar, novamente, o provável efeito aditivo da adição da fitase, aumento de $22 \mathrm{kcal} / \mathrm{kg}$ de MS.

Tabela 5 - Efeito da adição do complexo multienzimático (CM) sobre os valores de energia digestível ileal aparente $\left(\mathrm{EDI}_{\mathrm{ap}}\right)$, expressos em $\mathrm{kcal} / \mathrm{kg}$ de MS

Table 5 - Effect of enzyme supplementation on the apparent ileal digestible energy (apIDE) values, express in $\mathrm{kcal} / \mathrm{kg} D M$

\begin{tabular}{|c|c|c|c|c|}
\hline \multicolumn{2}{|c|}{$\begin{array}{l}\text { Enzima } \\
\text { Enzyme }\end{array}$} & \multicolumn{3}{|c|}{$\begin{array}{l}\mathrm{EDI}_{\mathrm{ap}} \\
I D E_{a p}^{\mathrm{ap}}\end{array}$} \\
\hline & & \multicolumn{3}{|c|}{$\begin{array}{c}\text { Nível Ca e } \mathrm{P}_{\mathrm{d}}^{1} \\
\text { Ca e } P_{a} \text { level }\end{array}$} \\
\hline & & $\begin{array}{l}\text { Normal } \\
\text { Normal }\end{array}$ & $\begin{array}{l}\text { Baixo } \\
\text { Low }\end{array}$ & $\begin{array}{l}\text { Média } \\
\text { Mean }\end{array}$ \\
\hline \multicolumn{2}{|c|}{ Controle } & $3219^{\mathrm{Ba}}$ & $3164^{\mathrm{Cb}}$ & 3192 \\
\hline \multicolumn{5}{|c|}{ Control } \\
\hline \multicolumn{2}{|c|}{$\mathrm{CM}^{2}$} & $3264^{\mathrm{Aa}}$ & $3204^{\mathrm{Bb}}$ & 3234 \\
\hline \multicolumn{2}{|c|}{ CM+ Fitase 3} & $3247^{\mathrm{AB}}$ & $3264^{\mathrm{A}}$ & 3256 \\
\hline \multicolumn{2}{|c|}{ Média } & 3244 & 3211 & \\
\hline \multicolumn{5}{|c|}{ Mean } \\
\hline \multicolumn{2}{|c|}{ Anova } & \multicolumn{3}{|c|}{$\begin{array}{l}\text { Probabilidade do teste } \mathrm{F} \\
\text { Probability F test }\end{array}$} \\
\hline \multicolumn{2}{|c|}{$\mathrm{Ca}$ e $\mathrm{P}_{\mathrm{d}}$} & \multicolumn{3}{|c|}{$<0,01$} \\
\hline \multicolumn{2}{|c|}{$\mathrm{CM}$} & \multicolumn{3}{|c|}{$<0,01$} \\
\hline \multicolumn{2}{|c|}{$\mathrm{Ca}$ e $\mathrm{P}_{\mathrm{d}} * \mathrm{CM}$} & \multicolumn{3}{|c|}{$<0,01$} \\
\hline \multicolumn{2}{|c|}{$\mathrm{CV}(\%)$} & \multicolumn{3}{|c|}{0,93} \\
\hline \multicolumn{5}{|c|}{$\begin{array}{l}\text { a, b Médias seguidas por letras distintas na mesma linha são } \\
\text { diferentes pelo teste } F(P<0,05) \text {. }\end{array}$} \\
\hline \multicolumn{5}{|c|}{$\begin{array}{l}\text { A, B Médias seguidas por letras distintas na mesma coluna são } \\
\text { diferentes pelo teste } S N K(P<0,01) \text {. }\end{array}$} \\
\hline & \multicolumn{4}{|c|}{ Níveis Ca e $\mathrm{P}_{\mathrm{d}}$ : normal $=1,00 \% \mathrm{Ca} / 0,45 \% \mathrm{P}_{\mathrm{d}}$ e baixo $=0,70 \% \mathrm{Ca} /$} \\
\hline$a, b$ & \multicolumn{4}{|c|}{ Means in the same line followed by different letter are different $(P<.05)$ by } \\
\hline A, B & $\begin{array}{l}F \text { test. } \\
\text { Means in the }\end{array}$ & \multicolumn{3}{|c|}{$\begin{array}{l}\text { olumn followed by different letter are different }(P<.05) \\
\text { test test. }\end{array}$} \\
\hline 1 & \multicolumn{4}{|c|}{$\mathrm{Ca}$ and $P_{a}: \mathrm{Normal}=1.00 \% \mathrm{Ca} / 0.45 \% P_{a}$ and $l o w=.70 \% \mathrm{Ca}: 32 \% P_{a}$} \\
\hline
\end{tabular}

Vários trabalhos reforçam os resultados encontrados no aumento do aproveitamento da energia. NAMKUNG e LEESON (1999) observaram melhora de $1 \%$ na $\mathrm{EMA}_{\mathrm{n}}$, pela dição de fitase, enquanto ZANELLA et al. (1999), pela adição de $0,1 \%$ de um complexos multienzimatico (protease, amilase e xilanase), em dietas à base de milho e farelo soja, também observaram melhora significativa de 2,5\% na EDIn. Estes dados sugerem que adição do complexo multienzimático e da fitase na dieta inicial de frangos de corte melhora a digestibilidade dos nutrientes e reforçam a hipótese do provável efeito aditivo observado com associação das enzimas. $\mathrm{O}$ fato de as enzimas serem específicas em suas reações sugere que misturas sejam mais efetivas no aproveitamento dos nutrientes das dietas, principalmente em pintos, os quais não apresentam desenvolvimento completo do sistema enzimático (Vanbelle, 1992, citado por BORGES, 1997).

Métodos tradicionais, utilizando enzimas em dietas à base de milho e farelo de soja, não incrementaram a digestibilidade dos nutrientes. No entanto, alguns estudos demostraram melhoras similares às encontradas neste trabalho (MARSMANN et al., 1997; RAVINDRAN et al., 1999; ZANELLA et al., 1999; e NAMKUNG e LEESON, 1999).

\section{Conclusões}

A adição da enzima fitase em dietas à base de milho e farelo de soja melhorou os coeficientes de digestibilidade médios da MS, PB e EB, os valores de energia digestível ileal aparente das rações e a digestibilidade do Ca e $\mathrm{P}$ em ambos os níveis de Ca e $\mathrm{P}_{\mathrm{d}}$.

A adição do complexo multienzimático melhorou a digestibilidade da MS, PB, EB, P e Ca. O complexo multienzimático mais fitase mostrou efeito aditivo na digestibilidade dos nutrientes.

A adição de misturas enzimáticas às dietas de aves pode ser economicamente viável em áreas onde o milho e o farelo de soja são os principais ingredientes utilizados.

\section{Referências Bibliográficas}

BEDFORD, M.R., CLASSEN, H.L., CAMPBELL, G.L. 1991. The effect of pelleting, salt and pentosanase on the viscosity of intestinal contents and the performance of broilers fed ryebased diets. Poult. Sci., 70:1571.

BIEHL, R.R., BAKER, D.H. 1997. Microbial phytase improves amino acid utilization in young chicks fed diets based on soybean meal, but not in diets based on peanut meal. Poult. Sci., 76:355-360. 
BORGES, F.M. 1997. utilização de enzimas em dietas avícolas. Cad. Tec. Esc. Vet. UFMG, 20:5-30.

CANTOR, A.H. Enzimas usadas na Europa, Estados Unidos e Ásia. Possibilidade para uso no Brasil. In: RODA LATINOAMERICANA DE BIOTECNOLOGIA, 5, 1995, Curitiba. Anais... Curitiba: Naval, 1995. p.31-42

FERKET, P. R. 1993. Practical use of feed enzymes for turkeys and broiler. J. Appl. Poult. Res., 1: 75-81.

MARSMANN, G.J., GRUPPEN, H. VAN DER POEL F.A. et al. 1997. The effect of thermal processing and enzyme treatments of soybean meal on growth performance, ileal nutrient digestibility, and chyme characteristics in broiler chicks. Poult. Sci., 76: 864-872.

NAMKUNG, H., LEESON, S. 1999. Effest of phytase Enzume on dietary Nitrogemn-corrected apparent metabolizable energy and ileal digestibility of nitrogen and amino acids in broiler chcks. Poult. Sci., 78:1317-1319.

RAVINDRAN, V., CABAHUG, S., RAVINDRAN, et al. 1999. Influence of microbial phytase on apparent ileal amino acid digestibility of feedstuffs for broiler. Poult. Sci., 78:699-706.

RIMBACH, G., PALLAUF, J. 1998. Phytic acid inhibits free radical formation in vitro but does not affect liver oxidant or antioxidant status in growing rats. J. Nut., 1950-1955.

ROSTAGNO, H.S., BARBARINO JR., P. BARBOZA, W. Exigências nutricionais das aves determinadas no Brasil. in: SIMPÓSIO INTERNACIONAL SOBRE EXIGÊNCIAS NUTRICIONAIS DE AVES E SUÍNOS, 1996, Viçosa, MG. Anais... Viçosa, MG: UFV, 1996. p.361-388.

STATISTICAL ANALYSES SYSTEM - SAS. 1989 - 1996. North Caroline State University, Cary, NC, USA Institute Inc.
SEBASTIAN, S., TOUCHBURN, S.P., CHAVEZ, E.R. et al. 1996. Efficacy of supplemental microbial phytase at different dietary calcium levels on growth performance and mineral utilization of broiler chickens. Poult. Sci., 75:1516-1523.

SEBASTIAN, S., TOUCHBURN, S.P., CHAVEZ, E.R. et al. 1997. Aparent digestibility of protein and amino acids in broiler chickens fed a corn-soybean diet supplemented with microbial phytase. Poult. Sci., 78:1760-1769.

SEBASTIAN, S., TOUCHBURN, S.P., CHAVEZ, E.R. 1998. Implications of phytic acid and supplemental microbial phytase in poultry nutrition: a review. World's Poult. Sci. J., 54:27-47.

SILVA, D.J. 1990. Análise de alimentos (Métodos químicos e biológicos). Viçosa: UFV. 166p.

SOHAIL, S.S., ROLAND, D.A. 1999. Influence of supplemental phytase on performance of broilers four to six of age. Poult, Sci. 78:550-555.

ZANELLA, I., SAKOMURA, N.K., SILVERSIDES, F.G. et al. 1999. Effect of enzyme supplementation of broiler diets based on corn and soybeans. Poult. Sci., 78:561-568.

Recebido em: 26/09/00

Aceito em: 14/02/01 